\title{
Системный и семантический анализ понятия «управление»
}

\author{
С.В. Микони \\ Санкт-Петербургский институт информатики и автоматизации РАН \\ smikoni@mail.ru
}

\section{Аннотация}

Обсуждается проблема понимания терминов предметной области. Сформулированы требования к составу и структуре определения понятий, отражающих различные виды деятельности, к которым относится и управление. Относительно этих требований выявлены недостатки существующих определений управления. Предложено обобщённое определение управления, цели которого согласованы с первым законом Ньютона. Связь между определяющими понятиями формализована с применением модели неоднородной семантической сети. Модель применима для представления различных уровней и способов управления.

Ключевые слова: определение понятия, валентность глагола, словообразовательное гнездо, управление, устойчивость, тип связи, семантическая сеть

Библиографическая ссылка: Микони С.В. Системный и семантический анализ понятия «управление» // Компьютерная лингвистика и вычислительные онтологии. Выпуск 3 (Труды XXII Международной объединенной научной конференции «Интернет и современное общество», IMS-2019, Санкт-Петербург, 19 - 22 июня 2019 г. Сборник научных трудов). - СПб: Университет ИТМО, 2019. С. 29 -39. DOI: 10.17586/2541-9781-2019-3-29-39

\section{1. Введение}

Использование в повседневной жизни глобальной сети Интернет позволяет её пользователям оперативно находить определения интересующих их понятий. Однако остаётся открытым вопрос о согласованности этих определений в среде специалистов. Другая проблема этих определений заключается в их локальном характере, в то время как понятия предметной области (ПрО) тесно связаны между собой. Проблема согласованности решается, в частности, в терминологических стандартах. Другим их преимуществом является возможность объединения понятий ПрО в систему. Качество терминологического стандарта определяется полнотой и непротиворечивостью системы понятий, положенной в его основу. Она используется при разработке терминологических стандартов в явном или неявном виде, но обычно не приводится в них в виде структурнофункциональной модели [1].

Терминология ПрО включает три составляющих: предметную, системную и языковую. Предметная составляющая представляет собой перечень терминов, необходимый и достаточный для отражения всех понятий, употребляемых в данной ПрО. К системной составляющей относятся связи между этими понятиями. К языковой составляющей относятся правила образования слов и предложений национального языка и выражаемый ими смысл. Лингвистический контроль терминологического документа обычно ограничивается морфологической и синтаксической проверкой его содержимого, а за смысл терминов и их определений отвечают предметники. Однако соблюдение правил грамматики не гарантирует соответствия смысла определения действительности.

Смысл, вносимый предметниками в определения понятий, влияет на связи между ними, т.е. на системную составляющую ПрО. Таким образом, качество терминологии 
существенно зависит от определений понятий и употребляемых для их обозначения терминов. На эту проблему обратил внимание известный американский учёный и практик в сфере управления и бизнеса Рассел Акофф. Свою последнюю книгу он посвятил обсуждению различий между часто и широко используемыми терминами языка менеджмента [2]. Он считал, что «многие разногласия и конфликты происходят вследствие того, что стороны употребляют один термин в разных смыслах».

Для обоснования своей трактовки видов руководителей он привлёк отношение «цельсредство»: администратор (чужая цель, чужие средства её реализации), менеджер (чужая цель, свои средства) и лидер (своя цель, свои средства). Осталась необозначенной пара (своя цель, чужие средства). Резонно эти качества отнести реформатору. Родовым понятием по отношению к обозначенным видам руководителей является управленец. Обоснованность соотношения терминов, предложенного Р. Акоффом, заключается в применении классификации, основанной на закономерности системного анализа [3].

В терминологическом документе [4], регламентирующем теорию управления, смысл многих вводимых понятий основывается на теоретических законах управления. Проблемы понимания терминов возникают там, где такие законы отсутствуют или неправильно трактуется смысл слов национального языка. К первой проблеме имеет отношение определение понятия «управление», предложенное в [4]. Оно определено как «процесс выработки и осуществления управляющих воздействий». Слово «управляющих» в определении понятия «управление» создаёт порочный круг, а цель управления осталась нераскрытой. Вторую проблему проиллюстрируем термином «выходное воздействие». Его смысл противоречит определению воздействия. В [5] оно определено как: «действие, влияние кого-то (чего-то) на кого-то (что-то)». Это что-то на выходе объекта отсутствует.

Подходом к созданию современных терминологических документов по управлению можно считать практически дословный перевод международных стандартов ISO 9000 с перекодированием ряда англоязычных терминов (например, management) на кириллицу. Уход от национального языка усугубляет ошибочное толкование используемых терминов, подмеченное Р. Акоффом в среде носителей английского языка.

Таким образом, актуальной задачей совершенствования терминологии управления является оценивание и уточнение смысла определений, употребляемых в ней понятий и применяемых для их обозначения терминов. Учитывая большой перечень терминов в области управления, в данной работе ограничимся рассмотрением понятия управления и определяющих его понятий.

\section{2. Качество предметной терминологии}

Качество предметной терминологии проявляется через однозначное и экономичное понимание её терминов. Количественно качество можно оценить отношением правильно понимаемых терминов к их общему числу. По своей природе термины, обозначающие понятия предметной области представляют собой разновидность знаков, а именно, словесные знаки [6]. Отсюда система понятий является знаковой (семиотической) системой. Понятность простых знаков объясняется их наглядностью, как чертой сходства с обозначаемым предметом (явлением). Примером тому являются дорожные знаки, например, знак «кирпич», как преграда движению.

По мнению английского философа Б. Рассела «сущность языка состоит в использовании фиксированных ассоциаций, т.е. в том, что нечто ощутимое произнесённое слово, картинка, жест и пр. - могло бы вызвать представление о чём-то другом. Когда это происходит, то ощутимое может быть названо знаком, символом, а то, о чём появляется представление, - его значением» [7, с. 131]. В естественном языке роль знака, символа играет слово, словосочетание.

Под экономичностью понимания термина будем понимать цепочку скрытых умозаключений от ощутимого к его представлению. Например, словосочетание 
«трансформащия данных» носитель русского языка будет вынужден перевести на русский язык как «преобразование данных», сделав лишний шаг к нахождению представления этого словосочетания. Именно поэтому современные тексты, перегруженные иноязычными терминами, неэкономичны с точки зрения их понимания носителями русского языка. Более того, во многих случаях иноязычные термины при буквальном переводе на русский язык являются ложно-ориентирующими [8]. Свежим примером является термин «Интернет вещей». Слово «вещь» в русском языке имеет более конкретное значение, чем слово «thing» в английском языке. Впрочем, термин «Internet of things» является ложно-ориентирующим и для носителей английского языка. Предложивший этот термин в 1999 году Кевин Эштон (Kevin Ashton) на самом деле обозначил им паутину физических объектов (things), т.e. Web of Things. И этот пример бездумного копирования иностранного термина, не разобравшись в его представлении, далеко не единичен. В этом смысле и поныне актуальны требования Петра Первого ${ }^{1} \mathrm{\kappa}$ переводчикам. По закону сохранения облегчение труда переводчиков оборачивается усложнением понимания их переводов.

Однозначности и экономичности понимания термина способствует наличие его образного (правополушарного) представления. «Наукой убедительно доказано, что только совместная деятельность обоих полушарий даёт нам наиболее адекватное восприятие действительности, характеризует нормальную психику и обеспечивает наиболее продуктивное познание окружающего нас мира» [7, с. 132]. Именно образ предопределяет полноценное понимание слова, задействуя оба полушария человеческого мозга. Возможность предоставления слова классом сходных образов позволяет считать естественный язык универсальной системой знакового моделирования действительности [6].

Свойству прямой наглядности не отвечают термины, обозначающие научные понятия. Вот, что писал Гейзенберг по этому поводу (цит. по [9]): «В нашу эпоху люди проникают в отдалённые, непосредственно недоступные для наших чувств области природы, лишь косвенно с помощью технических средств, поддающихся исследованию. В результате мы покидаем мир, в котором сформировался и для которого предназначен наш обыденный язык. Поэтому мы вынуждены изучать новый язык, во многих отношениях непохожий на естественный». Примером таких языков является язык математики, моделирующий абстрактное мышление. Однако при решении конкретных задач мы вынуждены интерпретировать математические символы, фактически занимаясь переводом (перекодировкой) с языка математики на предметный язык или, наоборот, с предметного языка на язык математики.

Свойством максимальной наглядности, обеспечивающей понятность терминов, должны обладать не только словесные знаки, но и связи между ними, что и характеризует терминологический стандарт как знаковую систему. Залогом его качества помимо профессионального опыта и соблюдения принципов системологии является знание грамматики русского языка и категорий обозначаемых им понятий. Чем точнее определён смысл каждого используемого слова, тем точнее находятся связи между соответствующими понятиями.

Смысл вводимого термина поясняется через слова с известным значением. Определение понятия задаёт, прежде всего, категорию общности пояснением его через понятие более общей логической категории. Набор наиболее общих (философских)

\footnotetext{
1 «И того ради надлежит вам и в той книжке, которую ныне переводите, остеречься в том, дабы внятнее перевести, а особливо те места, которые учат как делать, и не надлежит речь от речи хранить в переводе, но точно, смысл уразумев, на своем языке уже так писать, как внятнее может быть». Петр I «Указ Зотову об избегании в будущем ошибок».
} 
понятий можно рассматривать как систему аксиом (неопределяемых понятий). Другие понятия, входящие в определение, считаются известными, поясняя предметный смысл определяемого понятия. При этом ни одно из них не должно повторять определяемое понятие («порочный круг») [8].

Связи между понятиями ПрО не ограничивается связями обобщения (вид-род). В силу неоднородности понятий в модели ПрО используются также следующие типы связей: атрибутивная (иметь свойство, иметь значение), связь-присоединение (часть-агрегат) и её частный случай (часть-целое), связь-принадлежность (элемент-класс), связь-влияние (аргумент-функция). Разновидностями связи-влияния являются каузативная (причинаследствие), суммирующая, альтернативная и транзитивная связи [10].

Как к любой системе, к определению понятия предъявляются требования полноты, неизбыточности и непротиворечивости. Противоречивость определения проявляется через порочный круг. Полноту определения рассматриваемого в работе термина управление можно оценить через состав и число актантов (аргументов) глагола управлять (править) [11]. Для решения этой задачи используются вопросительные слова, характеризующие валентности этого глагола [12]. Их удобно перечислить через англоязычную группу вопросов 6W, включающих букву W: Who, What, Where, When, Why, How (буква W в конце слова) [13].

Ответы на первые два вопроса конкретизируют субъект и объект действия. Ответ на вопрос Why (Зачем? Почему?) объясняет цель действия. Ответ на вопрос How (Как?) поясняет сущность определяемого понятия (как устроено, как действует). Ответы на вопросы Where и When дают пространственно-временную характеристику действия, конкретизируя его во времени и в пространстве, что ёмко объясняется английскими словами time bond (ограниченное по времени) и place bond (ограниченное по месту нахождения). Однако пространственно-временная характеристика действия является избыточной для обобщающего понятия. Её использование влечёт переход определения в объяснение или инструкцию.

Для переходного глагола следует, прежде всего, указывать субъект (Who) и объект (What) действия. Субъект является активной составляющей действия, а объект пассивной составляющей независимо от их природы (живой или неживой). Под неживой природой здесь подразумеваются системы с управлением, создаваемые человеком. Особенность активной составляющей заключается в необходимости указания цели активности (вопрос Why).

Применим рассмотренные правила и принципы к анализу ряда определений термина управление.

\section{3. Анализ понятия «управление»}

Начнём с определения этого понятия, введённого в документе [4]. В качестве первого недостатка во введении было отмечено наличие порочного круга в этом определении.

Рассмотрим полноту этого определения относительно четырёх базовых актантов глагола «управлять». По существу, определение [4] отвечает только на вопрос Каким образом? (реализуется управление), характеризуя его как «выработку и осуществление управляющих воздействий». Ответы на другие вопросы даются во вспомогательных определениях.

Глагол управлять является переходным или двухвалентным [12], указывая перенос действия с одного объекта на другой. Это действие формализуется двухместным предикатом: Управлять (Субъект, Объект). Субъект представляет собой активную, а объект - пассивную составляющую управления. В терминах [4] субъект называется управляющим объектом, а объект - объектом управления или управляемым объектом. В этих терминах и определена в [4] система управления как «система, состоящая из управляющего объекта и объекта управления». 
Согласно этому определению самолёт, например, можно назвать «системой управления», поскольку он содержит как автопилот и другие органы управления, так и управляемый ими планер (корпус самолёта). С другой стороны, согласно данному определению система управления авиационным движением - автоматизированный сервис, обеспечиваемый наземными службами для управления воздушным движением, не является системой управления, поскольку не включает в себя объекты управления в отличие от самолётов, вошедших в зону ответственности соответствующей службы.

$\mathrm{C}$ точки зрения теории систем и управляющий объект (субъект управления) и объект управления сами по себе являются системами и в то же время частями общей системы, именуемой в соответствии со своим назначением. Самолёт - это система, включающая как систему управления (автопилот и пр.), так и управляемую систему (планер и пр.). В соответствии с [1] самолёт представляет собой монолитную (сосредоточенную в пространстве) систему, а система управления воздушным движением является частью (подсистемой) распределенной системы воздушного движения судов. Таким образом, система может быть сосредоточенной и распределенной в пространстве, а её подсистемы, распределённые в пространстве, могут выступать в качестве самостоятельных систем. Однако их самостоятельность относительна, поскольку в отсутствие самолётов система управления воздушным движением никому не нужна.

Таким образом, если систему управления отождествить с управляющим объектом (субъектом управления), то её определение в [4] содержит порочный круг. Избавиться от него можно заменой термина система управления на систему с управлением. Предложенное в [4] определение и задаёт состав этой системы.

Цель управления определена в [4] отдельно как «значения, соотношения значений координат процессов в объекте управления или их изменения во времени, при которых обеспечивается достижение желаемых результатов функционирования объекта». В этом определении совмещены пояснение решаемой задачи (первая часть определения) и общее определение цели (желаемые результаты функционирования объекта), не выделяющее особенности управления. Например, желание получить правильный результат вычисления на калькуляторе дважды два равно четырём (а не пяти) не имеет прямого отношения к управлению. Другим недостатком этого определения является смешение теоретических (координаты процессов) и содержательных понятий.

Рассмотрим другие варианты термина управление. В [14] он определен как «осуществление совокупности воздействий, выбранных из множества возможных на основании определённой информации и направленных на поддержание или улучшение функционирования управляемого объекта в соответствии с имеющейся программой или целью управления (алгоритмом функционирования)».

В этом определении отсутствует только ответ на вопрос Who (в определении отсутствует субъект воздействий). Помимо средств управления (воздействий) в нём сформулированы и обобщённые цели управления, как «поддержание или улучшение функционирования управляемого объекта». Дальнейшее пояснение управления - «в соответствии с имеющейся программой или целью управления (алгоритмом функционирования)» выглядит избыточным.

В отличие от этого определения актант, отвечающий на вопрос Who (субъект управления) включён в определение управления, данное в [1]: «выработка и осуществление иеленаправленных воздействий одного объекта (субъекта управления) на другой объект (объект управления)». Однако в этом определении исчезли обобщённые цели управления, сформулированные в [14]. Словосочетание иеленаправленное воздействие ничего не проясняет в отношении цели управления. Любая деятельность является целенаправленной. Это определение подойдёт, например, и к проектированию, если слово управление заменить словом проектирование. Субъектом проектирования является проектант, а объектом проектирования - создаваемый им проект. В отличие от 
обобщённых целей управления, сформулированных в [11] обобщённой целью проектирования является создание нового или модернизация существующего объекта.

Для обоснования обобщённых целей привлечём первый закон Ньютона. Согласно ему «всякое тело находится в состоянии покоя или равномерного прямолинейного движения, пока воздействие со стороны других тел не выведет его из этого состояния». Управляющее воздействие и требуется для того, чтобы вернуть тело «в состояние покоя или равномерного прямолинейного движения», чтобы устранить последствия внешнего воздействия. В его отсутствие управление не требуется. Сопоставив состоянию покоя «поддержание равновесия», а равномерному прямолинейному движению - «улучшение функционирования (развития)», мы и получим обобщённые цели управления, выделяющие его среди других видов деятельности.

Отвечающее этим целям и требованиям полноты определение управления было дано в работе [15]: «выработка и осуществление воздействий одного объекта (субъекта управления) на другой объект (объект управления), предназначенных для поддержания его равновесия или развития».

\section{4. Семантическая модель понятия «управление»}

На основе предложенного определения термина «управление» построим модель этого понятия в форме развивающейся семантической сети. Под её развитием будем понимать поэтапное раскрытие существенных признаков через поясняющие понятия. Модель определения термина, представляющего вид деятельности (действия) строится на основе порождающего звёздного графа, центральная вершина которого именуется глаголом (см. рис. 1). Дуги звёздного графа (изображены пунктиром) помечаются вопросами, соответствующими обязательным валентностям глагола.

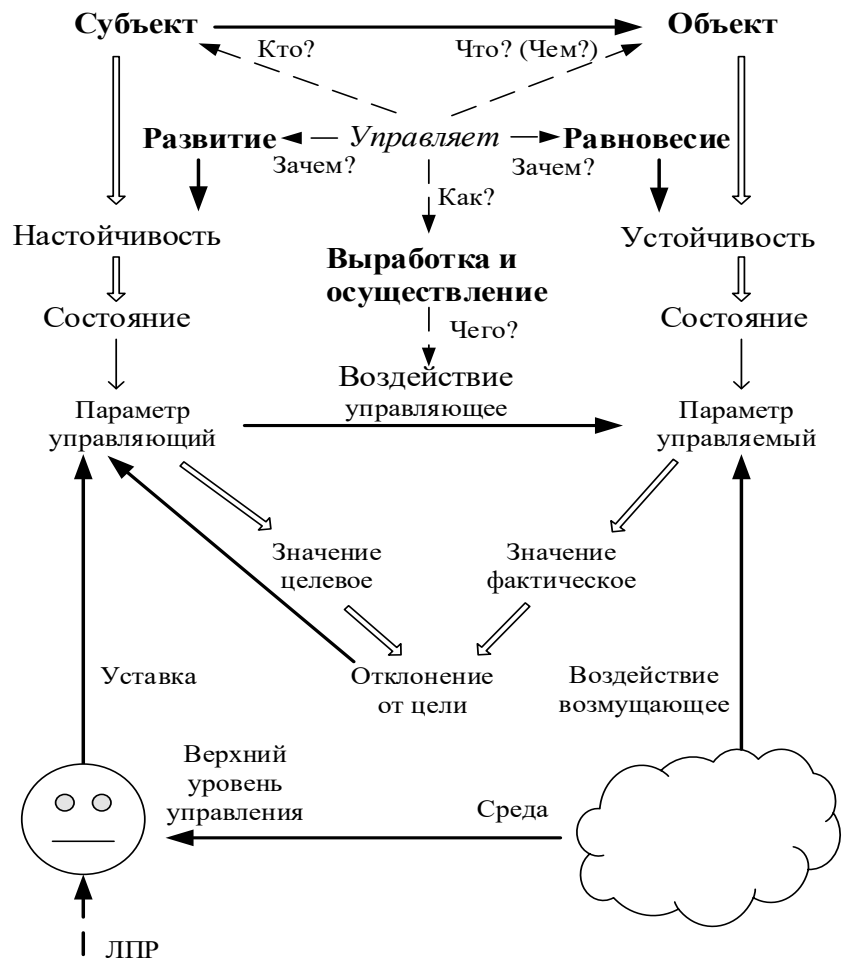

Рис.1. Семантическая сеть понятия «управление» 
Переходный глагол «управлять» имеет четыре обязательные валентности. Листовые вершины графа именуются актантами глагола. Они представляют собой существенные признаки понятия, на рисунке 1 выделенные жирным шрифтом. Актант «выработка и осуществление воздействий» конкретизирует глагол «управляет». Его аргументом является управляющее воздействие, которым помечена дополнительная вершина звёздного графа.

Как было отмечено выше, управляющее воздействие востребовано при наличии возмущающего воздействия, источником которого является внутренняя или внешняя среда системы с управлением. Включение возмущающего воздействия в модель определения понятия «управление» влечёт преобразование звёздного графа в неоднородную семантическую сеть. Её неоднородность объясняется различными связями между понятиями, перечисленными выше.

Поскольку возмущающее воздействие напрямую не связано с актантами глагола «управлять», для его включения в семантическую сеть требуется рассмотреть ряд связующих понятий. К таковым, прежде всего, относятся свойства субъекта и объекта управления. К ним отнесём настойчивость и устойчивость соответственно.

Состояние равновесия характеризуется устойчивостью объекта управления, а улучшение функционирования резонно характеризовать настойчивостью в достижении цели. Ведь, развитие обязательно имеет некоторую цель или совокупность целей. В [16] правомерно утверждается, что обеспечение устойчивости объекта управления по отношению к воздействиям окружающей среды является первичной целью управляющих воздействий. Содержательное определение понятия устойчивость в сборнике рекомендуемых терминов [4] отсутствует. Определены только такие видовые понятия как устойчивость абсолютная, асимптотическая, по Ляпунову, по части координат, при постоянно действующих возмущениях. В этих определениях фактически рассматриваются показатели устойчивости как различные виды отклонений параметров объекта управления от заданных величин.

Русскоязычное происхождение слов устойчивость и настойчивость проявляется через общее словообразовательное гнездо, имеющее корень стой (см. рис. 2).

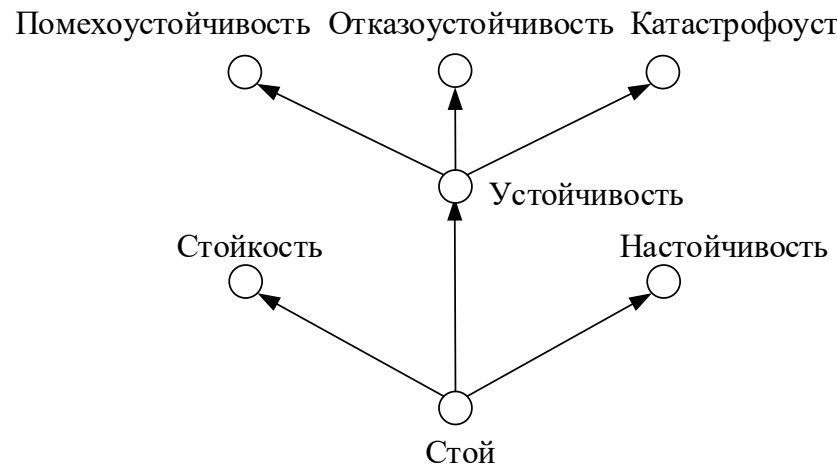

Рис. 2. Часть словообразовательного гнезда с корнем стой

Основной смысл глагола стой заключается в «нахождении в вертикальном положении, не двигаясь с места» [17]. Не двигаться с места следует трактовать как пребывание в покое (без изменений). Слово стойкость наиболее близко по смыслу слову стойкий (объект, долго сохраняющий свои свойства, не поддающийся разрушению). Именно в этом смысле понимается стойкость к физическим или химическим воздействиям, стойкость бойцов в бою. Таким образом, содержащие этот корень слова устойчивость и настойчивость 
также характеризуют неизменность некоторого свойства (свойств) при наличии возмущений.

Отглагольное существительное устойчивость образовано от глагола «устоять» с наиболее общим значением «не поддаться некоторому воздействию», т.е. сохранить свое состояние. Средством обеспечения устойчивости объекта является его сопротивляемость воздействиям. В этом смысле слово устойчивость определим, как свойство объекта выполнять свои функциии в условиях возмущающих воздействий внутренней и внешней cредbl.

Устойчивость объединяет такие свойства объектов, как прочность, стойкость к внешним воздействиям, надёжность, сбалансированность, стабильность, гомеостазис (способность системы возвращаться в равновесное состояние при выводе из него внешними воздействиями), живучесть. Устойчивость сложных систем дополняется свойствами адаптивности и проактивности.

Отглагольное существительное настойчивость образовано от глагола «настоять» с наиболее общим значением «достичь поставленной цели». Несмотря на то, что глагол достичь характеризует движение некоторой сущности, к нему может быть применено значение неизменности в достижении цели в условиях препятствия этому движению. Иначе говоря, слово настойчивость можно трактовать как устойчивость в достижении цели. Здесь следует отметить, что если устойчивость относится к объекту управления, то настойчивость относится к субъекту управления.

Помимо рассмотренных понятий на рис. 2 показаны помехоустойчивость, отказоустойчивость и катастрофоустойчивость как, своего рода, первые производные от слова устойчивость и вторые производные от корня стой. Отметим, что из словообразовательного гнезда отбираются только те производные слова, которые имеют отношение к управлению.

Поскольку первый закон Ньютона выражен через состояние тела, именно это понятие характеризует устойчивость и настойчивость рассматриваемой системы. Между этими свойствами объекта и субъекта управления и соответствующими им состояниями существует атрибутивная связь. На рис.1 она показана двойными стрелками.

Состояние формализуется кортежем параметров. Поскольку кортеж параметров можно трактовать как класс упорядоченных элементов, каждый параметр связан с состоянием связью «элемент-класс». На рис. 1 этот вид связи обозначен тонкими стрелками. Параметры, характеризующие состояние объекта управления, называются управляемыми, а параметры, характеризующие состояние субъекта управления - управляющими.

Управляющему параметру субъект управления задает целевое значение (уставку), а управляемый параметр объекта управления фиксирует фактическое значение. Оно отклоняется от целевого значения в результате возмущающего воздействия окружающей среды. Все виды воздействия, реализующие причинно-следственную связь, на рис. 1 показаны жирными стрелками.

В соответствии с теорией автоматического регулирования возникшее отклонение передается по обратной связи на субъект управления. Информация об отклонении управляемого параметра изменяет состояние субъекта управления. Согласно заданному закону управления, изменяется соответствующий управляющий параметр. Это изменение передается на объект управления с целью вернуть изменившийся параметр к первоначальному значению.

В иерархической системе управления уставки вырабатываются верхним уровнем самой системы (см. рис. 1). Внешний уровень управления представляет лицо, принимающее решение (ЛПР). 


\section{7. Заключение}

Условием повышения качества терминологической системы является рассмотрение её понятий во взаимосвязи с реальной или виртуальной действительностью, с применением закономерностей системного анализа, законов и правил языкознания. При формировании обобщённых понятий использованы богатые познавательные возможности русского языка. В частности, родство между обобщёнными свойствами субъекта и объекта управления обосновано отнесением их к общему словообразовательному гнезду.

Предложенная семантическая сеть понятия управление свободна от математической формализации и обладает высокой степенью общности относительно теории и практики управления. Она, в частности, проявляется в том, что не затрагиваются пространственновременные аспекты управления, соответствующие валентностям где? и когда? глагола управлять.

Общность предложенной модели позволяет принять ее за основу системы понятий управления. Модель открыта для представления различных уровней и способов управления от простейшего программного до проактивного и автономного управления (самоорганизации). При конкретизации области управления каждое из понятий модели подлежит дальнейшей детализации и конкретизации с включением в нее показателей и параметров, применяемых в теории управления.

Исследования, выполненные по данной тематике, проводились при финансовой поддержке грантов РФФИ № 17-01-00139, № 19-08-00989 в рамках бюджетной темы № 0073-2019-0004.

\section{Литература}

[1] Микони С.В., Соколов Б.В. Юсупов Р.М. Квалиметрия моделей и полимодельных комплексов. М.: PAH, 2018. 314 с. Издания Российской академии наук 2018. URL: http://www.ras.ru/publishingactivity/issues/collections.aspx?print=1 (дата обращения: 25.05.2019).

[2] Акофф Р.Л. Различия, которые имеют значение: Аннотированный глоссарий различий, важных для менеджмента / науч. ред. и пер. с англ. Ф.П. Тарасенко. Томск: Изд. Дом Том. гос. ун-та. 2016.

[3] Теория систем и системный анализ в управлении организациями. Справочник: учеб. пособие / Под редакцией В.Н. Волковой и А.А. Емельянова. М.: Финансы и статистика: ИНФРА-М. 2009.

[4] Сборник рекомендуемых терминов. Теория управления. Терминология. М.: Наука. 1988. Вып. 107.

[5] Современный толковый словарь русского языка / Под редакцией С.А. Кузнецова. М.: Ридерс Дайджест. 2004.

[6] Панов Е.Н. Знаки, символы, языки. М.: Знание. 1980.

[7] Полонников Р.И. Избранные труды в двух томах. СПб: «Анатолия». 2013. Т.1.

[8] Лотте Д.С. Основы построения научно-технической терминологии. М.: Изд-во АН СССР. 1961.

[9] Дирак П. Пути физики. М.: Энергоатомиздат. 1983.

[10]Микони С.В. Формализованный подход к установлению связи и роли понятий // Компьютерная лингвистика и вычислительные онтологии. Выпуск 2. - Труды XXI Международной объединенной конференции «Интернет и современное общество» IMS-2018. (Санкт-Петербург 30.05-2.06.2018). Сборник научных статей. СПб: Университет ИТМО. 2018. С. 75-84.

[11]Теньер Л. Основы структурного синтаксиса. / Пер. с франц. Вступ. ст. и общ. ред. В. Г. Гака. М.: Прогресс, 1988. 
[12]Hart G. The Five Ws of Online Help. TECH WR-L. Retrieved April 30. 2012.

[13]Кацнельсон С.Д. К понятию типов валентности // Вопросы языкознания. 1973. № 3. С. $20-32$.

[14]Статья «Управление» // Энциклопедия современной техники. Автоматизация производства и промышленная электроника. Под ред. А.И. Берга и В.А. Трапезникова. Т. 4. М.: Изд-во "Советская энциклопедия". 1965. С. 149-150.

[15]Микони С.В. Формализация определений понятий как условие повышения качества содержательных моделей. Сборник докладов XX Международной конференции «Мягкие вычисления и измерения» SCM-2017. (Санкт-Петербург 24-26.05.2017). СПб: СПбГЭТУ (ЛЭТИ). 2017. С. 19 - 22.

[16]Тарасенко Ф. П. Прикладной системный анализ: Наука и искусство решения проблем: учебник. Томск, 2004.

[17]Словарь русского языка. В 4-х т. РАН, Ин-т лингвистических исследований. Под ред. А. П. Евгеньевой. 4-е изд., стер. М.: Рус. яз. Полиграф. ресурсы. 1999.

\title{
System and semantic analysis of the concept of "control"
}

\author{
S. Mikoni
}

\section{St. Petersburg Institute for Informatics and Automation of the Russian Academy of Sciences}

The problem of understanding the terms of the subject domain is discussed. Requirements are formulated for the structure of the definition of concepts representing various types of activities, including control. Management is in the relation of inheritance to control, which is consistent with the classification of R. Ackoff. Regarding the formulated requirements, the deficiencies of the existing control definitions were revealed. A generalized definition of control is proposed, the objectives of which are consistent with Newton's first law. The relationship between the defining concepts is formalized using the model of a heterogeneous semantic network. The model is applicable to represent different levels and methods of control.

Keywords: definition of the concept, verb valence, derivational nest, control, stability, type of connection, semantic network

Reference for citation: Mikoni S. System and semantic analysis of the concept of "control" // Computer Linguistics and Computing Ontologies. Vol. 3 (Proceedings of the XXII International Joint Scientific Conference «Internet and Modern Society», IMS-2019, St. Petersburg, June 1922, 2019). - St. Petersburg: ITMO University, 2019. P. 29 - 39. DOI: 10.17586/2541-9781-20193-29-39

\section{Reference}

[1] Mikoni S.V., Sokolov B.V., Yusupov R.M. Kvalimetriya modelei i polimodelnih kompleksov. M.: RAN. 2018. URL: http://www.ras.ru/publishingactivity/ issues/collections.aspx?print=1 (access date: 25.05.2019). (In Russian).

[2] Ackoff R.L. Differences That Make a Difference, An Annotated Glossary of Distinctions Important in Management. Devon. Triarchy Press. 2010.

[3] Teoriya sistem i sistemnii analiz v upravlenii organizaciyami. Spravochnik: ucheb. posobie pod redakciei V.N. Volkovoi i A.A. Emelyanova. M.: Finansi i statistika INFRA-M. 2009.

[4] Sbornik rekomenduemih terminov. Teoriya upravleniya. Terminologiya. Vol. 107. M.: Nauka. 1988. (In Russian).

[5] Sovremennii tolkovii slovar russkogo yazika. Pod redakciei S.A. Kuznecova. M.: Riders Daidjest. 2004. (In Russian).

[6] Panov E.N. Znaki, simvoli, yaziki. M.: Znanie, 1980. (In Russian). 
[7] Polonnikov R.I. Izbrannie trudi v dvuh tomah. Tom 1. SPb: «Anatoliya». 2013. (In Russian).

[8] Lotte D.S. Osnovi postroeniya nauchno-tehnicheskoi terminologii. M.: Izd-vo AN SSSR. 1961. (In Russian).

[9] Dirak P. Puti fiziki. M.: Energoatomizdat_1983. 88 p. (In Russian).

[10]Mikoni S.V. Formalizovannii podhod $\mathrm{k}$ ustanovleniyu svyazi i roli ponyatii // Kompyuternaya lingvistika i vichislitelnie ontologii. Vipusk 2. Trudi XXI Mejdunarodnoi obedinennoi konferencii «Internet i sovremennoe obschestvo» IMS-2018. (SPb.: 30.052.06.2018). Sbornik nauchnih statei. SPb.: Universitet ITMO. 2018. P. 75-84. (In Russian).

[11]Tener L. Osnovi strukturnogo sintaksisa. / Per. s franc. M.: Progress. 1988. (In Russian).

[12]Hart G. The Five Ws of Online Help. TECH WR-L. Retrieved April 30. 2012.

[13]Kacnelson S.D. K ponyatiyu tipov valentnosti // Voprosi yazikoznaniya. 1973. № 3. P. 20-32. (In Russian).

[14]Statya "Upravlenie". Enciklopediya sovremennoi tehniki. Avtomatizaciya proizvodstva i promishlennaya elektronika. Pod red. A.I. Berga i V.A. Trapeznikova. Tom. 4. M.: Izd-vo "Sovetskaya enciklopediya". 1965. P. 149-150. (In Russian).

[15]Mikoni_S.V. Formalizaciya opredelenii ponyatii kak uslovie povisheniya kachestva soderjatelnih modelei. Sbornik dokladov XX Mejdunarodnoi konferencii «Myagkie vichisleniya i izmereniya»SSC_2017. (SPb. 24-26.05.2017) SPb.: SPbGETU (LETI). 2017. P. 19-22. (In Russian).

[16]Tarasenko F. P. Prikladnoi sistemnii analiz. Nauka i iskusstvo resheniya problem. Uchebnik. Tomsk: 2004. (In Russian).

[17]Slovar russkogo yazika $v$ 4-h. tomah. RAN Institut lingvisticheskih issledovanii. Pod red. A. P. Evgenevoi. 4-e izd. ster. M.: Rus. yaz. Poligraf. Resursi. 1999. (In Russian). 